Regards sur l'économie allemande

Bulletin économique du CIRAC

116-117| 2015

Varia

\title{
Allemagne : site stratégique pour les filiales françaises
}

Isabelle Bourgeois

\section{OpenEdition}

Édition électronique

URL : http://journals.openedition.org/rea/4827

DOI : $10.4000 /$ rea. 4827

ISSN : 1965-0787

Éditeur

CIRAC

\section{Édition imprimée}

Date de publication : 1 juillet 2015

Pagination : 71-72

ISSN : 1156-8992

\section{Référence électronique}

Isabelle Bourgeois, «Allemagne : site stratégique pour les filiales françaises », Regards sur l'économie allemande [En ligne], 116-117 | juillet 2015, mis en ligne le 01 juillet 2017, consulté le 15 septembre 2020. URL : http://journals.openedition.org/rea/4827

Ce document a été généré automatiquement le 15 septembre 2020.

(c) CIRAC 


\title{
Allemagne : site stratégique pour les filiales françaises
}

\author{
Isabelle Bourgeois
}

1 La presse française "fustige une approche prétendument déséquilibrée de la coopération franco-allemande", s'insurge très diplomatiquement la chambre de commerce et d'Industrie Française en Allemagne (CCFA). Le Germany-bashing généralisé l'a incitée à récolter directement l'avis des acteurs de terrain. D'octobre 2014 à avril 2015, la CCFA et les Conseillers du Commerce Extérieur de la France (Section Allemagne) ont donc mené une enquête auprès des plus de 4000 filiales françaises installées en Allemagne, dont les résultats ont été présentés à Paris le 24 juin 2015.

\section{Un tremplin pour le développement en Europe}

2 Ses conclusions sont instructives. On s'aperçoit que l'image véhiculée dans l'espace politico-médiatique ne correspond en rien au vécu des filiales françaises. Pour elles, l'Allemagne est un site stratégique et doublement porteur : en termes d'image, puisque leur localisation leur octroie le précieux label made in Germany, et en termes de positionnement sur le marché européen, l'Allemagne étant la plate-forme d'échanges par excellence avec les pays est-européens. $79 \%$ des filiales considèrent donc ce label " comme un tremplin» sur lequel elles s'appuient pour développer leurs échanges avec les pays voisins. $58 \%$ d'entre elles « exportent plus de $20 \%$ de leur CA à partir d'Allemagne et $34 \%$ plus de $50 \%$ ». Quant au marché allemand à proprement parler, il présente à leurs yeux un énorme potentiel de croissance, pour leur maison-mère et encore plus pour elles-mêmes.

\section{Avantages concurrentiels : prélèvements raisonnables et flexibilité interne}

Les avantages concurrentiels d'un site de production en Allemagne s'imposent à l'évidence. La fiscalité des sociétés est jugée favorable, voire très favorable (une large moitié des réponses). Il en va de même des charges patronales: les deux tiers des filiales françaises les considèrent comme favorables/très favorables. Elles apprécient également le droit du travail (50\% d'avis favorable/très favorable), les coûts salariaux (53\%) et la flexibilité interne aux entreprises (65\%). Les acteurs économiques français 
vivent donc au quotidien l'impact positif sur l'activité des réformes de la protection sociale et l'effort de flexibilité des partenaires sociaux.

\section{Bonne opinion des relations sociales et du style de management}

De même, ils sont très satisfaits $(72 \%)$ des conventions tarifaires de branche qui apportent une grande prévisibilité et une garantie de paix sociale, surtout dans l'industrie et les services liés aux entreprises. En ce qui concerne les relations sociales au sein de l'entreprise, les avis sont moins nets : $42 \%$ seulement pensent que «le climat social dans l'entreprise est très avantageux"; pour la moitié, la question est neutre. Les réponses sont proches lorsqu'on les interroge sur leur perception des relations avec le Conseil d'établissement (Betriebsrat) : $44 \%$ d'avis neutres, $49 \%$ de favorables. On peut voir là les effets des fortes divergences culturelles entre nos deux pays dans le management des entreprises, car les réponses à la question de savoir comment les filiales françaises perçoivent le style de management en Allemagne sont hésitantes elles aussi : pour près de $35 \%$, la situation est neutre, alors que pour un peu plus de $43 \%$, elle est favorable (très favorable : 14,4 \%). Les dirigeants français apprécient la «logique d'autorité peu hiérarchique et une approche opérationnelle très délégationnelle», comme l'explique cette étude. Néanmoins, cette logique semble parfois entrer en conflit avec le style d'autorité pyramidale tel qu'il est enseigné et pratiqué en France. L'étude fait apparaître toutefois que les méthodes de management allemandes sont perçues de manière favorable/très favorable $(57,6 \%)$ par les états-majors français et en déduit "que les pratiques allemandes seront l'objet d'un benchmarking permanent ".

\section{Un vivier de main-d'œuvre qualifiée}

5 En matière de ressources humaines, les filiales françaises plébiscitent la formation professionnelle dans le système dual (67\%). Et la moitié d'entre elles apprécie le multilinguisme $\mathrm{du}$ vivier de managers, directeurs financiers, commerciaux ou ingénieurs. Mais - et elles partagent ce point de vue avec les sociétés allemandes -, elles sont préoccupées ( $40 \%$ par la pénurie naissante de main-d'œuvre qualifiée. Quant à la hausse sensible des salaires au cours des dernières années, elle les laisse sereines (35 \%).

L'Allemagne est clairement, pour les PME et les grands groupes français, «un marché de référence et de déploiement vers d'autres débouchés voisins". La présence française en Allemagne est honorable, certes, mais elle ne se situe qu'en $7^{\mathrm{e}}$ position, loin derrière les Pays-Bas, la Suisse, les Etats-Unis, le Royaume Uni, l'Autriche et le Luxembourg. La renforcer encore présente un intérêt stratégique pour la compétitivité de l'économie française à l'international. Cela présuppose toutefois la maîtrise de la langue et de la culture allemandes...

\section{INDEX}

Mots-clés : Comparaison franco-allemande, compétitivité, concurrence, croissance, délocalisation, investissement, sondage 